\title{
Mendívil, Julio. En contra de la música. Buenos Aires: Gourmet Musical Ediciones, 2016, 192 pp.
}

En contra de la música es el aporte personalísimo de su autor para todo aquello que resulta urgente y necesario reafirmar en momentos de una truculenta virada global a la derecha que occidente vive en los últimos años: un manifiesto para devolvernos al significado más primordial del humanismo crítico, de una comprensión holística del musicar (por usar la verbalización propuesta por Christopher Small) polisémico y agregador, en franca oposición a la música, sustantivación universalizadora y manipulación ideológica que, hoy por hoy, puede convertirse en un verdadero acto de violencia física, simbólica, política y económica.

Desde ya prevengo al lector de que este libro no tiene por finalidad revelarnos un verdadero sentido del campo de lo sonoro que convencionalmente conocemos bajo el nombre de Música, escrito esta vez con mayúscula por referirse a un área de conocimiento específico. Valiéndose no solo de una sólida trayectoria profesional sino también de una sensibilidad personal atenta a los mínimos detalles, Mendívil se propone y consigue contagiarnos de las discusiones que originaron los diversos análisis que componen la publicación, en temas que atraviesan debates vigentes y polémicos como la identidad nacional, la patrimonialización de legados materiales (ej.: instrumentos musicales) e inmateriales (ej.: géneros musicales), los procesos de globalización, los discursos y regímenes de verdad sobre el concepto de música, el impacto social de las tecnologías de la información, entre otros aspectos.

Los referenciales teóricos sugeridos son un dato etnográfico coherente y riquísimo que nos informa constantemente; parafraseando a Renato Rosaldo, el sujeto posicionado que nos escribe y reflexiona acerca de la diversidad de tópicos mencionados. En mi opinión, este es un acto político contrario al ideal de neutralidad y distanciamiento, uno de los postulados metodológicos más ferreños y negativamente intransigentes en relación con la producción académica y que constantemente gana proporciones de regla natural cuando se piensa en trabajar musicológicamente desde el ámbito universitario. En su lugar, y en sintonía con los postulados de Feyerabend, Mendívil nos ofrece una aula de pluralismo metodológico al tejer una polifonía que invoca los diversos escenarios de sus actos personales, profesionales y académicos, enunciándonos de forma rizomática — por citar una figura deleuziana - la gran variedad de interlocutores provenientes, a su vez, de diversos escenarios: la escena académica germánica y los efectos de su 
inmersión sobre el schlager alemán, la escena peruana arguediana y las vivencias fruto del estudio y relación con el charango, entre otras (más recientemente, su experiencia y convivencia intensa como miembro de la rama latinoamericana de IASPM, por ejemplo).

Pese a la diversidad de temas repletos de situaciones y de interrogantes provocadoras e intrigantes - mucho más necesarias para generar conocimiento que los textos que nos dan respuestas, creo yo- resulta evidente su preocupación en un asunto transversal que reiteradamente nos alerta el libro desde diversos enfoques: el dogmatismo y su instrumentalización a través de la música.

Una de esas alertas se encuentra en las críticas a los dogmas que definen la palabra música (ej.: como en los títulos «Sobre el origen de la música», «¿Tiene sentido hablar de música?», «¿Qué significa saber de música?», «¿Qué es la música clásica?», «¿Cómo definir las músicas?») definición que a su vez implica perpetuar analogías oscuras sobre el desarrollo de las culturas bajo conceptos evolucionistas inspirados en el paradigma darwiniano. A este tópico en particular yo le agregaría el impacto de aquello que se erigió como sede legislativa, ejecutiva y judicial del pensamiento evolucionista en la música: la creación de un espacio físico institucionalizador de la práctica musical humana, a la sazón, los conservatorios.

Otra de las alertas antidogmáticas está presente en las disertaciones sobre la música y sus efectos políticos y separatistas al servicio de discursos chovinistas de la pureza nacional, de rescate a las raíces, de defensa de lo nuestro (ej.: «¿A qué llamamos folclor?», «La música y el paisaje», «La música y los vínculos territoriales», «La música y el nacionalismo», «Sobre nacionalismos y el origen de los instrumentos musicales», «La patrimonialización de la música»). Después de leer estos recortes me pregunto: ¿estamos frente a semillas de fascismos culturales que practican la militancia de patrimonios materiales o inmateriales de un país con el fin de ganar el aval de la Unesco? Estas prácticas, inspiradas por románticos y folcloristas de la cultura popular - por evocar la tipificación de Renato Ortiz-, precisan con urgencia ser discutidas públicamente bajo preceptos etnomusicológicos que entiendan la cultura desde la historia de sus migraciones - humanas y, por extensión, culturales en lo material e inmaterial-, así como de la circulación de estos no solo en circuitos históricos y territoriales sino también en circuitos de los medios masivos, como García Canclini advierte en Consumidores y ciudadanos. El tema resulta muy importante para Mendívil, como profesor universitario, como etnomusicólogo, como peruano de la diáspora y como intérprete de charango. El autor nos pide que prestemos atención al 
creciente tono beligerante de la disputa por el supuesto origen de este cordófono y de cómo ello, lejos de documentar y constatar la naturaleza capilar y resiliente del charango y sus recorridos organológicos y sociales, aparece como símbolo xenófobo en el corazón de una cultura andina multinacional ajena — desde siempre- a cualquier delimitación cartográfica.

Otros asuntos también aparecen enriquecidos por la diversidad de escenarios que Mendívil coloca a disposición en sus ensayos, como por ejemplo la mención a los embates apocalípticos — aquí el autor parafrasea Umberto Eco- de la concepción de música frente a la socialización exponencial postinternet (léase Spotify, Facebook, monetización, views, likes, google analitycs, ad targeting, etc.). En títulos como «La música como mercancía», el autor nos ofrece de alguna forma una mirada atenta a la industria de la música que no necesariamente pasa por una defensa de las Majors fonográficas y sí por un intento de sacarnos de lugares comunes y dicotómicos (ej.: Majors versus «independientes»). Es cierto que las así llamadas indie labels no son necesariamente una panacea y que mucho de lo que entendemos por piratería de la música es un ejercicio de contrabando simbólico nefasto, muy lejano del intercambio de archivos entre usuarios (léase tecnología peer-to-peer), el concepto de copyleft o el uso de licencias creative commons. Sobre este particular me salta aún una duda: ¿en qué momento hablamos de comercialización en cuanto actividad que tornó asequible la música y cuándo esta comercialización impone barreras a su utilización, difusión o modificación? La música como mercancía también parece ser un espacio para pensar la vigencia de términos como hegemonía y resistencia, pues su comercialización también se organiza a partir de relaciones de poder concretas y desiguales (ej.: ¿cuánto vale un disco compacto en Lima y en Nueva York? ¿Cuántas personas consiguen pagar y tener (pues implica una tecnología 3G, por lo menos) una subscripción de Spotify sin dudarlo un instante siquiera?

En contra de la música es un libro necesario para todos aquellos que son músicos, que aprecian la música, que discuten sobre música en diversos ambientes y escenarios. Su lectura se vuelve obligatoria, en mi opinión, en países como el Perú, y no por razones simples y obvias (ej.: Mendívil es peruano de nacimiento y usa ejemplos de ese país). Cuando considero su lectura urgente lo hago pensando en la cruda y franca realidad de la discusión musicológica y musical que nuestro país tiene en relación con esta práctica social y al repertorio simbólico que todos reconocemos pero no necesariamente conocemos o comprendemos. Enfrascados en discusiones conservatoriales de alta y baja cultura, cuando no en argumentaciones de los tiempos de Carlos Vega o José María Arguedas, 
o alienados por jazzificaciones ad hoc y yuxtaposiciones e injertos musicales (ej.: latin fusion, world music, etc.), los argumentos sobre la música en territorio peruano no consiguen dialogar ni dudar sobre su originalidad: son análogos a los discursos sobre la comida peruana: unánimes y verticales. En contra de «esa» discusión sobre la música y en favor de muchas discusiones plurales, migrantes, (re) significadas, globales y locales (antes que peruanas per se), el libro de Mendívil es una invitación a salir de nuestra zona de confort cultural, de huir de la caverna de Platón al encuentro de paisajes repletos de sonidos humanamente organizados.

Fernando Elías Llanos Fundação das Artes de São Caetano do Sul fllanos@usp.br

\section{REFERENCIAS BIBLIOGRÁFICAS}

García Canclini, Néstor (1995). Consumidores y ciudadanos. México D.F.: Editorial Grijalbo.

Ortiz, Renato (1992). Românticos e folcloristas: cultura popular. São Paulo: Editora Olho d'agua.

Rosaldo, Renato (1989). Culture and Truth. The Remaking of Social Analysis. Boston: Beacon Press.

Small, Christopher (1998). Musicking: The Meanings of Performing and Listening. Connecticut: Wesleyan University Press.

\section{Resumen}

El libro recorre por diversos tópicos vigentes y polémicos que la música provoca en nuestro día a día: el concepto de música y su pretensa universalidad, su relación con la identidad — nacional y global — y las formas en que esta opera, para bien y para mal, en una sociedad intermediada por las tecnologías de la información.

Palabras clave: nacionalismo y música, discursos sobre la música, relaciones de poder y música.

Keywords: nationalism and music, discourses on music, power relations and music. 